\title{
A Discussion of Foreign Language Listening Problems and Their Causes among Intermediate EFL learners in Chinese universities
}

\author{
Zhiyi Zhu* \\ School of Foreign Languages, Guangdong Peizheng College, Guangzhou 510830, Guangdong Province, China \\ *Corresponding author: Zhiyi Zhu, 869578429@qq.com
}

\begin{abstract}
Listening has been considered as the most important language skill by many researchers but in Chinese context it has been overlooked for years. The Foreign Language (FL) listening problems gradually reveal when students attend to the Listening Course in universities or colleges. This paper at first illustrates the importance of listening in foreign language learning and provides a discussion on the top-down and bottom-up processes with the analysis of Anderson's three-model of language comprehension ${ }^{[9]}$ as well as the factors affecting listening comprehension in Foreign Language in general, aiming at the illustration of the necessity on one of the bottom-up processes - the Spoken Word Recognition (SWR). The analysis of two issued official guiding documents for Chinese university students and the current situation of English listening teaching in Chinese universities are followed, providing a general background on English listening teaching in Chinese context. Three possible foreign language listening problems and their causes are proposed, followed by the pedagogical suggestions to EFL learners who are improving their listening skills and instructors who are advancing their teaching procedures.
\end{abstract}

Keywords: Foreign Language Listening; Intermediated EFL learners; Chinese universities; Spoken Word Recognition; Listening teaching

Publication date: August 2021; Online publication: August 30, 2021

\section{Introduction}

Listening is the most frequently used language skill in everyday life. It is suggested that people cannot help hearing speech in their first language (L1), which does not mean, however, that this skill is simple. In fact, it is a very complex skill that difficult to acquire in a foreign language (FL) or second language (L2), and at the same time the most important one for language acquisition.

In terms of listening as a FL, there is one thing should be highlighted that the notion of English as a Foreign Language (EFL) and English as a Second Language (ESL) is slightly different. English in EFL context is not used in people's everyday life, where people have less frequent opportunities to expose in English. The typical EFL countries includes China, Korean and some others. In contrast, people in ESL context such as Hong Kong, Singapore, India have more exposure of English in many daily occasions. However, many researchers considered there is no big difference between FL learning and L2 learning ${ }^{[1]}$. When discussing the involving process of FL listening, it may be technically similar to the L1 learning ${ }^{[2,3]}$. This paper therefore would integrate the theories of L2 listening and L1 listening to further explore the problems that may arise in the practical application of FL listening and to discuss its impact on listening comprehension. 


\subsection{Top-down and bottom-up processing}

The top-down processing and the bottom-up processing are two major cognitive processes involving in listening comprehension, which have attracted many researchers ${ }^{[2,4,5,6]}$. In reality, listening works as a combination and complementary of top-down processing and bottom-up processing but the degree of using each processing is not usually the same. It largely depends on the purpose of listening ${ }^{[3,4]}$. Listening is also a construction of the meaning based on information from a number of knowledge sources applied through iterative cognitive processes ${ }^{[8]}$. The top-down processing emphasizes the application of context and prior knowledge to interpret the intended message when the words segmentation is failed, which serves as a compensatory strategy for the bottom-up model, while the bottom-up processing starts with the segmenting the sound stream, and then the combining into meaningful units, and later interpreting the intended message, which are developed through practice in word segmentation skills ${ }^{[2,5,8]}$. Spoken word segmentation thus is an essential and indispensable process no matter listeners keen on which process. Recognising the English sounds in the connected speech and applying other kinds of knowledge to organize a mental representation of the spoken text assist the EFL listeners process a meaning listening activity.

\subsection{Anderson's three-phase model of language comprehension}

Anderson's ${ }^{[9]}$ model might provide a different insight on language comprehension process and listening construction. He proposed a three-phase interconnected cognitive listening model of language comprehension, which comprises perception, parsing, and utilization. With perception being the lowest, these three phases are different levels of processing, which can be ordered in time or at the same time ${ }^{[5,10]}$. This model also illustrates the interaction and connection between top-down and bottom-up processing.

Perception phase refers to the usage of bottom-up processing to recognize phonemes, pauses, and acoustic emphases, and holding these in Working Memory (WM). This is the initial phase in the word segmentation process. Retaining perceptual processing is a major challenge for FL listeners because recognizing and identifying word boundaries are involuntarily applied to an L2. Difficulties reported in the perception phase are mainly related to the recognition of distinct words or groups of words, the failure of attention and others $[10,11]$.

In the parsing stage, when segmenting the connected speech, the brain breaks up the phonological information by means of the cues of linguistic knowledge such as phonological knowledge, syntactic knowledge, and semantic knowledge, and recombines the broken phonological information into meaning representations and retained recombined information in short-term memory. FL listeners however need to selectively attend to the input due to the limited capacity of WM, which may cause their inability to form a coherent mental representation from words heard.

Finally, utilization phase relates the resulting meaningful units to information stored in the long-term memory (LTM) to interpret the intended meanings and primarily involves the top-down processing. Using prior knowledge and pragmatic knowledge stored as schemata in LTM and context knowledge, listeners elaborate on the newly parsed information and monitor this interpretation for congruency with their schemata and the evolving representation of the text in memory. Listeners however may encounter problems in this phase that link to the understanding the intended message for lacking the prior knowledge or the inappropriate application of prior knowledge ${ }^{[10,11]}$.

In short, segmenting listening processes into multi-phases, suggesting that listening is a process where all phases work simultaneously to decode and encode the input messages. Anderson's ${ }^{[9]}$ three-phase model of language comprehension provides an accurate diagnosis on listening difficulties because it identifies various phases where the process might be interrupted. The problems of bottom-up processing occur at the perception stage, the difficulties in the top-down processing belong to the utilization stage, and the problems of the interaction between the bottom-up and the top-down processing are involved in the parsing stage. As 
for FL listeners, with limited linguistic knowledge, they may not be able to automatically process all the linguistics information they received, which takes them more time and effort to efficiently coordinate these processes.

\section{Factors affecting listening comprehension in Foreign Languages}

Many factors affect English listening comprehension without a define conclusion on the exact number of factors and classification involved in English listening. However, these factors can be mainly generated into three categories, the characteristic of the listener, passage, and testing conditions ${ }^{[12]}$.

In terms of the characteristics of the listener, three main areas have been discussed which were cognitive area, linguistic area and affective area ${ }^{[5,12]}$. The cognitive area is related to listener's general cognitive abilities such as working memory capacity that regulates the top-down and the bottom-up processing, metacognitive strategies that supports listening in tasks. While the linguistic aspect focuses on listener's proficiency and previous experience including the amount of prior exposure to the language, familiarity with and an ability to understand the target language's phonology, vocabulary size, and background knowledge about the topic, text, structure, schema, and culture. The third aspect is affective area involving two important variables, anxiety and motivation ${ }^{[5,12]}$.

There are four main dimensions related to characteristics of passage, which are passage length, passage complexity, passage organization, and auditory features. Each characteristic consists of several subcharacteristics. To specified, overall length, information density and redundancy affect the first characteristic-passage length-on FL listening comprehension. Passage complexity comprising syntactic features, directness, concreteness, and pragmatic information may also affect FL listening comprehension. Several dimensions of organization affect comprehension including orality, coherence, discourse markers, and position of relevant information, while auditory features including speaker accent, disfluencies, noise, distortion, and speech rate ${ }^{[12]}$. Test conditions including time limits, the time and timing of hearings, and decisions about notetaking affect the FL listening comprehension ${ }^{[12]}$.

The above review and summary of the relationship between the factors affecting listening comprehension shows that FLL is a complex process engaging diverse features. Listening comprehension being an interactive and integrated model involving the top-down processing and the bottom-up processing, engages other objective factors such as the characteristics of passage and test conditions. Listeners compensate for listening comprehension difficulties by improving and perfecting subjective factors, and then reach full understanding. However, more-skilled and less-skilled FL listeners regulate these processes differently.

Researchers who have investigate the interaction between the top-down processing and bottom-up processing suggest that less-skilled listeners tend to rely on the bottom-up processing because in their shortterm memory, no sufficient capability can be used to process and activate prior knowledge of subjects, and the reliance on contextual clues ${ }^{[13,14]}$. This suggested that word segmentation skills of less-skilled listeners are fragile, which lower the subsequent processes - parsing stage and utilization stage. Goh ${ }^{[10]}$ pointed that lower proficiency listeners with limited or inadequate abilities in SWR interrupted the overall listening comprehension. Insufficient usage of the bottom-up skills to apply the quick word recognition is one of the major problems for less-skilled listeners ${ }^{[15]}$. The development of word segmentation is a major challenge for FL listeners ${ }^{[16]}$.

In listening comprehension, listeners can only segment continuous stream of speech into words and phrases by phonological knowledge, such as stress patterns, assimilations, elisions and others, which is much more challenging than reading comprehension where readers can determine each word boundaries by word spaces. Listeners who fail to recognise spoken words within 1000-2000 frequency bands in connected speech had to guess by top-down processing. However, no matter what level the FL listeners are 
at are more reliant on bottom-up processing for decoding, especially encountering fast speech ${ }^{[2]}$.

SWR is a basic and initial bottom-up skill in listening comprehension. The bottom-up processing is primary for EFL listeners at intermediate level as they have to segment words into meaningful word groups first in order to active top-down cognitive and metacognitive strategies such as guessing meaning or relating new information to what they already know. As the bottom-up processing is an essential and important processing for FL listening comprehension, EFL learners especially lower-levels are in need of more fundamental knowledge training such as features of connected speech, frequently used spoken vocabulary to progress SWR skills. By advancing the SWR skills, short term memory can have more space and capacity to allocate for other listening stage, and further develop and enhance the overall listening comprehension.

\section{Teaching English listening in Chinese context \\ 3.1. Guiding documents}

Listening comprehension has been considered as a very important component in the field of Foreign Language Acquisition (FLA) ${ }^{[4,6]}$. For Chinese EFL learners, listening as an indispensable input skill helps them enhance their English ability. Listening seems to have been evaluated to unprecedentedly high level in teaching English in Chinese universities, and the importance of teaching and learning listening has been widely recognised. This section discusses the changes of two official guidelines on English in Chinese context, and the widespread practice on teaching English listening in Chinese universities.

Since 2004, the Ministry of Education of China has conducted the College English Curriculum Requirements (For Trial) ${ }^{[17]}$. In this document, the ELT requirements has been divided into three levels of requirements, the basic requirements; the intermediate requirements; and the higher requirements. The basic requirements in listening comprehension indicates that listeners are supposed to follow classroom instructions, daily conversations, and lectures on general topics conducted in English, and at a speed rate at around 130 words per minute. The intermediate requirements in listening comprehension indicates that listeners should be able to follow talks and lectures by native speakers, to understand longer English radio and TV programs produced in China, to understand course in their areas of specialty taught by foreign teachers in English. The speed rate at this requirement is around 150 words per minute. The higher requirements indicates that listeners are expected to understand longer dialogues and passages with complicated structures and implicit opinions, to understand the radio and TV programmes produced in English-speaking countries, to understand lectures related to their areas of specialty. The speed rate is not explicitly indicated in the higher level of requirements. In the next decade or so, this document has been a guideline for publishing and revising a variety of English listening materials, and a protocol of listening teaching objectives in Chinese universities.

In 2018, China's Standards of English Language Ability (CSE) ${ }^{[18]}$ was proposed and applied, considering the unified standards of various English tests in China, the insufficient recognition of comprehensive language ability, and the low international approval of English tests in China. Compare to College English Curriculum Requirements (For Trial), CSE has a more thorough and precise partition in the light of English levels of Chinese speakers. First, with three development levels and nine bands, the features of various English language abilities among Chinese EFL learners are indicated in CSE. Three development levels that are beginner level, intermediate level, and advanced level. Each level assigns to three subordinate bands of English abilities. EFL learners whose English ability is at the First Band to the Third Band are labelled as the beginner level learners. The intermediate level learners are those English ability graded from the Fourth Band to the Sixth Band, and the advanced level learners are graded at the Seventh Band to the Ninth Band. Second, CSE provides specific and detailed descriptions on various English abilities including language comprehension ability, language production ability, organizational competence, and pragmatic ability, by three kinds of tables, which are tables of overall ability, tables of 
sub-skills, tables of self-evaluation. Among them, tables of overall ability are generally describing the overall English ability, listening comprehension ability, reading comprehension ability, speaking production ability, writing production ability, organizational competence, interpretation ability and translation ability. While tables of sub skills are describing various cognitive abilities and strategies. Different language abilities are estimated from various dimensions. In the light of listening comprehension ability, it is specified into six sub-dimensions, comprehending the spoken description; comprehending the spoken narration; comprehending the spoken exposition; comprehending the spoken instruction; comprehending the spoken discussion; comprehending the spoken interaction. As for the intermediate level learners, they are expected to achieve the following standards. To be specific, EFL listeners who are at the Fourth Band are expected to understand the overall context of personal-related speech, non-academic lectures, news reports, and to distinguish the essential and non-essential information. They should also understand the conversation concerned with familiar topics and the intended opinions of speakers. At the Fifth Band, EFL listeners are supposed to understand the expression, to obtain the details and key points; to define the coherence; and to understand the cultural-related meanings on general topics. They, also, should be able to understand the overall context when watching or listening TV programmes on general topics. The Sixth Band EFL listeners are expected to understand the lectures, reports, and discussions in their areas of specialty; to assure the cohesion and coherence of the listening context; and to understand the workplace conversations, such as business negotiations, interviews and others. When it comes to speed rate, intermediate level EFL learners (the Fourth Band to the Sixth Band) are supposed to follow the normal speed rate that is 100-140 words per minutes. In short, CSE still maintains the basic requirements on listening comprehension in College English Curriculum Requirements (For Trial), it however made proper modifications in terms of comprehension dimensions and requirements. Third, CSE provides tables of selfevaluation, which is a dominant innovation apart from defining more explicit descriptions and tables of overall ability and sub-skills. Tables of self-evaluation are more likely to assist Chinese EFL learners to acquire a clear picture of their own English language level, and appropriately adjust their English learning approach, strategies and focus, which reflects the increasing importance of learners.

These two official documents indicate the focus on the improving Chinese EFL learners' competence in listening comprehension, which increasingly stresses the importance of listening and the utilization stage. However, if Chinese EFL listeners do not have a good command of the perception stage related to the bottom-up stage, SWR specifically, they may frustrate on extract and understand the intended message in the connected speech, and also unable to balance the interaction and integration of top-down and bottomup processes.

\subsection{English listening teaching in universities}

\subsubsection{Monotonous listening forms and inauthentic listening materials}

The monotony of listening forms and the lack of authenticity of listening materials are two dominant problems of English listening teaching in Chinese universities. The vast majority of the teaching aids attaching with the coursebooks are in audio form ${ }^{[19]}$. Tedious listening forms diminish the diversity and dynamic of teaching formats and also reduce the teaching efficiency and students' motivation. Inauthentic listening materials is another dilemma for both teachers and listeners. In Chinese university, most published listening coursebooks are compiled and revised by Chinese scholars according to Chinese students' learning characteristics, learning levels and learning abilities, which then be recorded by natives with 'standard' pronunciation and accent ${ }^{[19]}$. The rhythm, intonation and even the diction of these artificial listening materials are very different from those in real communication. 


\subsubsection{Monotonous teaching procedures}

At present, most English listening teaching in China adopt the subsequent model - listening to the attached audio recording, check the answer, listening to the teachers' explanation ${ }^{[19]}$. Non-participatory listening is most found in listening course where students listen to audio and video recordings of selected spoken texts, such as short lectures and talks, and answer comprehension questions by writing answers, filling in the blanks, completing diagrams and tables, taking notes, and selecting multiple choices. The programmatic nature of the classroom dilutes the actual communicative function of language, resulting in students attending non-participatory listening in the language class access less freedom, and in most situations no freedom on exerting various cues and reception strategies, such as non-verbal cues, cultural-bounded cues, clarification requests ${ }^{[11]}$. Students therefore may perceive higher tension when attending non-participatory listening in the class. In addition, students are expected to correctly finish as many listening comprehension exercises as possible within the setting time and limited times of the audio played by the teacher. This requires students have demanding cognition on processing the input in a short time and clarifying their understanding and then answering the comprehension question. As this process requires a demanding level of cognitive ability, it is undoubtedly very difficult and stressful for students at a lower level.

In short, the teaching model of listening courses in Chinese universities is one textbook with a few cassettes, focusing on practicing listening comprehension of whole texts and using comprehension questions to demonstrate whether students understand the texts. It emphasizes the declarative knowledge over the procedural knowledge. The efficiency and effectiveness of improving listening abilities would be greatly diminished if listeners are forced into such kind of passive and high-pressure situation for a long time.

\section{Possible Listening Problems and Their Causes in Chinese Students}

SWR is a basic and essential bottom-up processing in the perception phase of listening comprehension, as listening as a continuous process is based on phonemic and syllabic discrimination and lexical processing. However, it should be noted that listening comprehension requires more than SWR. In terms of SWR, it is not simply recognising spoken words by identifying where the phonemes start, how they blend into one another, and how they form words. It involves two synchronous tasks, the identification of phonological words and lexical phrases, and the activation of knowledge associated with target words and phrases ${ }^{[20]}$. The identification of phonological words and lexical phrases evokes a process of estimate lexical units and boundaries within larger phonological groupings ${ }^{[6]}$. The recognition of spoken words is more than recognising a single word, but activating its relevant word knowledge including lexical units (word forms; part of speech, lemma) and frame relation (collocations, case relationships, extended senses) ${ }^{[6]}$. These two tasks are highly related to lexemes.

In SWR, there are six possible causes of listening difficulties involving word-level processing, ignorance of the word; knowing the written form of the word but not accessing its spoken form; confusing the word with one with similar pronunciation; knowing the spoken form of the word but not identifying it in connected speech; recognising the spoken form of the word in connected speech but not activating its meaning in the lexicon; perceiving the spoken form of the word but mismatching its meaning ${ }^{[21]}$. The first four possible reasons link with the identification task, while the rest two are related to the activation task. The forthcoming section discuss the possible reasons of Chinese students' listening difficulties from the perspectives of identification and activation.

\subsection{Problems at the identification stage}

Three dominant causes involving the first task - the identification of phonological words and lexical phrases are lacking listening vocabulary; unfamiliar with English pronunciation systems and word forms; having 
difficulty in breaking down the stream of speech.

\subsubsection{Lacking listening vocabulary}

A serious challenge and significant problem for Chinese university students at the intermediate level of English is lacking listening vocabulary. Recognising phonological information correctly is fundamental for listening comprehension. Lack of the lexeme information of phonological form and orthographic form, Chinese EFL learners are incapable to recognise the frequently arose words, which is a major barrier affects the listening comprehension of English learners with Chinese background ${ }^{[22-24]}$. Pemberton ${ }^{[24]}$ conducts six experimental studies on the more frequent words in English from BBC new items among Hong Kong intermediate level learners. He concludes that comprehension is like to be severely hampered if the listeners can reach only this level of word recognition, and suggests that full comprehension would be 'extremely unlikely reached with recognition rates of $75 \%$ and below ${ }^{[24]}$.

\subsubsection{Unfamiliar with English pronunciation systems and word forms}

As English and Chinese have vastly different pronunciation systems and word forms, students have some difficulties in identifying by sound the words they know in writing.

First, different phonemes in any two languages are not the same, thus, Chinese EFL learners need to acquire a new set of phonemes in learning English. It could be problematic when acquiring new sounds for a new language because Chinese EFL learners tend to assimilate English phonemes to their established L1 system, Chinese phonemes system ${ }^{[2]}$. Vowels are always at the approximate length in Chinese. Thus, Chinese EFL learners have problems on distinguishing the vowel length in continuous speech. Furthermore, they find it difficult in distinguishing English vowels that do not exist but sound similar in Chinese phonemes, such as $/ \partial /$ and $/ \Lambda /$, /ai/ and others.

Second, the convention of tone groups are quite different between Chinese and English. In Chinese, different tones on the same syllable can express different meanings. There are four pitch movement on a word in mandarin resulting a change in distinctive meaning. For example, the same syllable ma, has four different meanings as the pitch changes: high level ma (mā) refers to '妈' (mother), high-rising ma (má) refers to “麻' (hemp), low-falling ma (mă) refers to “马’ (horse), high-falling ma (mà) refers to ‘骂' (scold). Compared to Mandarin, it is unexpected for this effect to be achieved with pitch movement on only one word in English because in English each tone group has one syllable as more heavily stressed and accompanied by a pitch movement (the tonic syllable), thus creating intonation. Intonation patterns provide important meaning and the tonic signals new or important information, usually occurring near the end of the tone group ${ }^{[2]}$. It is effortless to understand why sense the emotional changes of the interlocuters in English listening or conversations are challenging for Chinese EFL listeners.

Third, homophones and heteronym are prevalent in Chinese language. For example, '停' (stop) and ‘庭' (court) pronounce ‘tíng', ‘悲剧’ (tragedy) and ‘杯具' (cups) pronounce 'bēijù’; ‘行’ pronounces 'xíng' in ‘行走' (walking) but 'háng' in ‘行列’ (line), ‘单' pronounces 'shàn' as a monosyllabic surname but 'chán' as a compound surname but 'dān' in '单车' (bicycle). In fact, the number of homophones and heteronym in Chinese far outweighs that in English. Differences between the intonation patterns and the tonic in English and in Chinese may cause misunderstanding utterances, resulting in the raising difficulty on lexemes recognition and segmentation for Chinese EFL listeners. If they are unfamiliar with English vocabulary in either spoken or written form, they would be poor in decoding sound input. With poor decoding ability, the limited short-term memory capacity should be relocated more on bottom-up processes, especially the perception stage, delaying and interrupting the top-down processes and then breaking and halting the thorough and effective comprehension on the connected speech. 


\subsubsection{Difficulty in breaking down the stream of speech}

Students who cannot segment speech find listening difficult. Unlike reading where EFL readers know the word boundaries with the help of the space, the problem for EFL listeners is that so much disappears in the stream of normal speech that it is not clear to them how many words there are supposed to be in the utterance and where the boundaries might lie ${ }^{[25]}$. The assimilated and the elided form of words in the connected speech are different from the full and the explicit form encountered in coursebooks ${ }^{[2]}$. In the connected speech, the word boundaries are not completely marked in the connected speech, and they often be blurred by phonological phenomena ${ }^{[26]}$. In listening to connected speech, spoken language does not perceive as a series of sounds which then be divided into words. In naturally occurring speech of English speakers, the boundaries between words become blurred because individual words are not in isolation but run into one another (assimilation) or may be reduced or left out (elision) or be alternated by other sounds.

Along with the difficulty in breaking down the stream of speech caused by the phonological phenomena, various pronunciation is another important factor influencing the recognition and segmentation. In fact, English native speakers would have various pronunciations on both vowels and consonants because of their social classes and living areas. The disparity of assorted pronunciations frequents every day, but it differs from the 'standard' English introduced and taught in coursebooks. Chinese EFL listeners have problems in recognising the assimilated form, the elided form as well as other alternative form of words in the connected speech if they had been teaching the 'standard' phonological descriptions of English that based on an idealized full form derived from individual words.

Word stress and sentence stress in English connected speech disturb the listening processes for Chinese EFL listeners. With English as a stress-timed language, content words in sentences are usually stressed while grammatical words or function words are usually unstressed. The unstressed words tend to be spoken faster and weaker than the stressed words. For example, some function words such as 'the', 'of', 'and', 'a', 'in' being the top five in the most frequent 50 words forms in the BNC ${ }^{[27]}$ are usually pronounced as a schwa, which are not pronounce as clear and precise as they are in isolation. Stress, in addition, conveys meaning by indicating importance, which can for emphasis only or for contrast ${ }^{[1]}$. In connected speech, English words tend to be spoken in stressed or unstressed form for maintaining the overall rhythm. On the other hand, Chinese as a syllable-timed language, every syllable tends to have the same duration ${ }^{[2]}$. An unfamiliar rhythm can interfere significantly with a listener's ability to recognise known words in connected speech ${ }^{[21]}$. Thus, Chinese speakers, with a syllable-timed L1, encounter listening problems when learning a new language belonging to a different rhythm.

In short, lack of adequate listening vocabulary, unfamiliar with English pronunciation system and unable to segment the connected speech are three dominant listening problems for Chinese EFL, which cause the unsuccessful operation of the identification of phonological words and lexical phrases and slower the process of SWR and then disrupt the global comprehension of the listening texts.

\subsection{Problems at the activation stage}

Two listening problems involves the second task - the activation of knowledge associated with target words and phrases are recognising the spoken form of the word in connected speech but not activating its meaning in the lexicon and perceiving the spoken form of the word but mismatching its meaning ${ }^{[21]}$, which means fail to match oral form with its meaning in the mental lexicon. There are two possible reasons for these problems - no meaning to match in the mental lexicon; or the meaning is mismatched.

\subsubsection{No 'meaning' nodes in the mental lexicon}

Mental lexicon is like a web where phonological knowledge, orthographical knowledge and meanings are nodes in it. When one node is activated, its signal will soon be sent to activate its connected nodes, but 
whether the target nodes could be activated depend on the connection between them and the first activated node.

Chinese college learners perceived in listening comprehension is unable to match the sounds with the meaning represented ${ }^{[23]}$, which is say in mental lexicon, the node 'phonological form' fail to activate the target node 'meaning' because of the inexistence of the target node 'meaning'. Without the target node, the activation process fails, interrupting the upcoming stage on parsing the phonological message. No 'meaning' nodes in the mental lexicon results from the lack of or the instability of comprehending and acquiring listening vocabularies, because knowing a single word minimally entails knowing its form and its meaning.

\subsubsection{Mismatch the phonological forms and meanings}

Listeners can be able to recognise and activate the spoken form and the written form of a vocabulary but fail to match its meanings. From psychological linguistics perspective, both 'forms' node and 'meanings' node exist in listeners' mental lexicon but the connection between these nodes are not strong and solid enough for activation in a short time, resulting in the mismatch between 'forms' node and 'meanings' node. Ineffective activation interrupts the forthcoming parsing and reduces the efficiency of listening comprehension. Thus, knowing the form and the meaning of a single word is far more enough. Knowing the relationship between the two is essential.

In sum, establishing 'meanings' nodes especially the common meanings of high frequency words in listening and their derivations in the mental lexicon is the foundation. On this basis, strengthening the connections between spoken forms and meanings and increasing the rate at which students activate the nodes is the key to improve their listening comprehension.

\section{Pedagogical Implications}

Considering the current situation of listening teaching in Chinese universities and colleges and the dominant listening problems appeared in Chinese EFL intermediate listeners, how to make improvements in English listening teaching and learning is an issue that needs to be addressed. Three suggestions are proposed in the section: improving the size and the depth of listening vocabulary; familiarize the use of English pronunciation system and intonation; improving the accuracy of word segmentation in the connected speech.

\subsection{Improving the size and depth of listening vocabulary}

Teaching vocabulary and its meanings is not enough to enrich the language leaners' mental lexicon ${ }^{[28]}$. Advancing the size (numbers of the known words) and depth (how well the words are known) of listening vocabulary should be affirmed, because Chinese EFL learners are lack of listening vocabulary, fail to match or mismatch the phonological forms and meanings.

First, teachers can list the words from listening materials that worth learning or may diminish students' listening comprehension such as frequent words, key words, difficult words, big words in advance. Students learn these word forms and meanings by themselves before the class, which establish new nodes in mental lexicon such as phonological, orthographical and morphological node, semantic and syntactic node, as well as build the relationship between nodes. In the class, the established nodes and their relationships will be strengthened and build up connections between these 'new' nodes and other 'old' nodes via various teaching activities. For example, dictating single words intensify students' phonological and orthographical knowledge; dictating sentences including the target words enhance students' morphological, semantic and syntactic knowledge; making sentences by adopting target words and others build up the connection between the target words and the 'old' nodes. Using short and simple pre-listening teaching activities to begin with builds up familiarity with well specified areas of vocabulary because adult learners have general prior knowledge that equip them for effective and intelligent guesses about the structures and the 
vocabularies used in the context ${ }^{[25]}$. In this way, new nodes can be activated and strengthened in learner's mental lexicon, and be connected with the established nodes for subsequent multi-channel activation, increasing the efficiency of activation in the second stage.

\subsection{Familiarizing the use of English pronunciation system and intonation}

Lacking intensive English learning environment is an unavoidable deficit for Chinese EFL learners. The ultimate goal for ELT instructors is to help EFL listeners understand the English material in everyday life, allowing listeners to be exposure in authentic-type texts and natural speech rate. If EFL listeners want to improve the sensibility of English pronunciation system and the use of intonation, they should consciously and explicitly increase the input of English language via large amount of extensive listening practices with abundant topics. Large amount of extensive listening practices is the basic for sensing English language system in an effortless way. Practices for extensive listening include but are not limited to the coursebookattached audios; teacher-elected listening material; English-made films; participatory listening. As for the choice of topic, it should be related to students' study and life such as life in campus, and heated and ongoing topics such as Covid-19 and Tokyo Olympic Games. The difficulty of extensive listening practices should start from the easy to the difficult. However, there few authentic listening materials appropriate for lower proficiency EFL listeners due to their inadequate vocabulary listening size and the speed rate. Slowing down the speech rate is not necessarily helping for comprehension purposes ${ }^{[29]}$. Thus, adapted listening materials with more familiar words and normal speed rate can reduce EFL learner's frustration and increase their motivation in the classroom ${ }^{[8]}$. Comprehensive improvement of the sensibility of English pronunciation system and the use of intonation base on sufficient and practical extensive listening practices. Another factor weakening the understanding of the English material is the variant of English. In fact, the number of non-native English speakers outweighs that of native English speakers. For non-native English speakers, speaking English with their national characteristics cannot be ignored and avoided due to the language and cultural factors. For example, Indian English speakers are much more likely to mix the voiced and voiceless sounds such as $/ \mathrm{t} /$ and $/ \mathrm{d} /, / \mathrm{p} /$ and $/ \mathrm{b} /$ with the articulation rules of Indian. Japanese English speakers possibly use the sounds in gojūon to substitute the non-existed sounds such as /v/, /r/ and /l/ in their language. Influenced by the strong syllable stress of Japanese, Japanese usually segment and pronounce the various stress in a word into the same stress. The inability of comprehending the intended message immediately sometimes is due to the listeners' unfamiliarity with the pronunciation system of the speaker's language, rather than the words in the connected speech. Thus, a proper understanding and a systematic study of theory on the differences between interlingual pronunciation systems and the common usage of intonation in different languages assist listeners to improve the efficient comprehensiveness of extensive listening, and may also reduce listening anxiety and ease the fear of difficulty. This may somewhat increase the efficiency of listening comprehension for Chinese EFL listeners as discerning the proper pronunciation rules in different languages.

Apart from the learning of various English pronunciation system, the use of intonation as a phonological knowledge should be noted as well due to the different intonation patterns between Chinese language and English language. It is a myth that in English, the intonation of question tags rises only while the intonation of statements falls only. However, there is no strict rule of intonation. Rising tone and falling tone can be used in both questions and statements, depending on the speakers' purpose. For instance, falling tone would be used if the speaker asks for confirmation. A series of rises and a final fall are usually heard for listing and addressing. Thus, teachers or instructors should clarify the myth in order to let students notice the actual usage of intonation.

In short, the effective and efficient way for familiarizing English pronunciation system and the usage of intonation is applying the proper understanding and comprehension of theoretical knowledge into 
extensive listening practices.

\subsection{Improving the accuracy of word segmentation in the connected speech}

Chinese EFL listeners have difficulty in segmenting the words in the connected speech because they are unfamiliar with the stress in English language, especially on sentence level. Stress on sentence level is easily ignored by Chinese EFL learners, though it does not influence the overall comprehension at times. However, the implied meaning may be different with different stressed words in the same sentence. For example, words 'called', 'other side' and 'street' are usually stressed in the sentence 'she called me from the other side of the street'. If the speaker intends to stress the word 'me', the implied meaning would be: not others but ' $m e$ ' is the one she called. Chinese EFL listeners are inclined to misinterpret the implied meaning elicited by the stress due to the stress pattern of their L1. Thus, teaching the rhythm of English language would help learners notice the way of stressing in English. Rhythm is the most symbolic characteristic of the spoken form of a language and the most difficult to master ${ }^{[25]}$. As a stress-timed language, the rhythm of English is based on the contrast of stressed and unstressed syllables. The rhythmic beat in English consists of stressed syllables, while unstressed syllables will be compressed between the stressed syllables ${ }^{[25]}$. As a stress-timed language, the rhythm of English is based on the contrast of stressed and unstressed syllables. The rhythmic beat in English consists of stressed syllables, while unstressed syllables will be compressed between the stressed syllables ${ }^{[25]}$. In English, the pronunciation of individual words will change when they link together with each other in utterances. Function words (grammatical words) such as conjunctions, prepositions, pronouns indicate the relations of the intended information, which are usually pronounced in weak form in the connected speech. These functions words are usually pronounced as a schwa, which are easily missed out. While in Chinese language each syllable is pronounced with the same amount of stress, hence, unstress is a very difficult thing for Chinese EFL learners. Paying attention to the stressed syllables in the stream of speech may help learners to recognise words and phrase boundaries, and then identify units which carry most information ${ }^{[5]}$.

Stressing could be usefully practiced with the simple poems such as nursery rhymes, limericks and others. In addition, dictation is an effective bottom-up approach to learn phonological features because it requires high attention on decoding the connected speech and identifying content words, and strengthens memory to keep one chunk of meaningful speech in mind until the chunk was written ${ }^{[5]}$.

Students thus can improve the identification of word stresses with the help of poems reading and sentence or paragraph dictation.

\section{Conclusion}

The study contributes to listening comprehension in SWR in general and in the Chinese university context in particular. SWR should attain ample attention from both teachers and students because of its importance portrayed in the bottom-up process. Improving listening comprehensive skills is a long-term process. Having a comprehensive knowledge on listening problems and their causes among the target students helps teachers to assist students to overcome the fear of difficulty, to activate their motivation on active listening, and to apply various proper listening teaching methods for strengthening students' listening strategies and skills, improving their listening ability, as well as advancing the quality of listening teaching.

\section{Disclosure statement}

The author declares that there is no conflict of interest. 


\section{References}

[1] Bailey KM, 2018, Teaching Listening and Speaking in Second and Foreign Language Contexts. Bloomsbury Academic. London.

[2] Flowerdew J, Miller L, 2005, Second Language Listening: Theory and Practice. Cambridge University Press, Cambridge.

[3] Newton JM, et al. 2018, Teaching English to Second Language Learners in Academic Contexts: Reading, Writing, Listening, and Speaking. Routledge, London.

[4] Field J, 2008, Listening in the Language Classroom. Cambridge University Press, Cambridge.

[5] Kurita T, 2012, Issues in Second Language Listening Comprehension and the Pedagogical Implications. Accents Asia, 5(1), 30-44.

[6] Rost M, 2011, Teaching and Researching Listening. $2^{\text {nd }}$ edn. Longman, Harlow.

[7] Vandergrift L, Goh C, 2012, Teaching and Learning Second Language Listening. Metacognition in Action. Routledge, New York.

[8] Vandergrift L, 2007, Recent Developments in Second and Foreign Language Listening Comprehension Research. State of Art Article. Language Teaching, 46(3), 191-210.

[9] Anderson JR, 2009, Cognitive Psychology and its Implications. $7^{\text {th }}$ edn. Worth Publishers, Macmillan.

[10] Goh C, 2000, A Cognitive Perspective on Language Learners' Listening Comprehensive Problems. System, 28, 55-75.

[11] Vandergrift L, 2011, Second Language Listening: Presage, Process, Product, and Pedagogy. In Hinkel E, (Ed.) Handbook of Research in Second Language Teaching and Learning, Routledge, London, 2: 455-471.

[12] Bloomfield A, et al. 2010, What Makes Listening Difficult? Factors Affecting Second Language Listening Comprehension. Maryland Univ College Park.

[13] Hansen C, Jensen C, 1994, Evaluation Lecture Comprehension. In: Flowerdew J, (Ed.), Academis Listening. Cambridge University Press, Cambridge, 241-268.

[14] Schmidt-Rinehart BC,1994, The Effects of Topic Familiarity on Second Language LC. The Modern Language Journal, 78, 179-189.

[15] Pemberton R, 2004, Spoken Word Recognition in a Second Language: An Investigation of the Ability of Hong Kong Learners to Recognize the Most Frequent Words of English When Listening to News Broadcasts. Language Centre, The Hong Kong University of Science and Technology, HK.

[16] Cutler A, 2000, Listening to a Second Language Through the Ears of a First. Interpreting, 5(1): 123.

[17] College English Curriculum Requirements (For Trial), viewed 06 August 2021, http://www.moe.gov.cn/srcsite/A08/s7056/200401/t20040130_110837.html

[18] China's Standards of English Language Ability (CSE), viewed 06 August 2021, http://www.moe.gov.cn/srcsite/A19/s229/201804/t20180416_333315.html

[19] Yang H, Zhao J, 2018, Multiculturism and Contemporary English Teaching. Tianjin Science and Technology Press, Tianjin.

[20] Rost, M., 2002, Teaching and Researching Listening. Longman, Harlow.

[21] Field J, 2009, Listening in the Language Classroom. Cambridge University Press, Cambridge.

[22] Goh C, 1999, How Much Do Learners Know About the Factors that Influence Their LC? Hong Kong Journal of Applied Linguistics, 4(1): 17- 39.

[23] Gao LP, 2008, Bottom-Up Speech Recognition: An Investigation into the Impact of the Ability to Recognize the Frequent Words of English on Listening Comprehension for Chinese College 
Students at Intermediate and Upper-Intermediate Proficiency Levels. (MA Dissertation). University of Nottingham, Nottingham.

[24] Pemberton R, 2009, Acting on a Hunch: Can L1 Reading Instruction Affect L2 Listening Ability? In: T. Fitzpatrick, \& A. Barfield. (Eds), Lexical Processing in Second Language Learners. Multilingual Matters, 141-153.

[25] Brown G, 1990, Listening to Spoken English. $2^{\text {nd }}$ edn. Longman, London.

[26] Dahan D, Magnuson JS, 2006, Spoken Word Recognition. In Handbook of Psycholinguistics. Academic Press. 249-283.

[27] Leech G, Rayson P, Wilson A, 2001, Word Frequencies in Written and Spoken English. Longman, Harlow.

[28] Pranoto BE, Afrilita LK, 2018, The Organization of Words in Mental Lexicon: Evidence from Word Association Test. Teknosastik, 16(1), 26-33.

[29] Jensen ED, Vinther T, 2003, Exact Repetition as Input Enhancement in Second Language Acquisition. Language Learning, 53(3), 373-428. 